\title{
ANÁLISIS DE LA IMPLEMENTACIÓN DE UN PROGRAMA EDUCATIVO BASADO EN LA METODOLOGÍA MOBILE LEARNING
}

\section{ANALYSIS OF THE IMPLEMENTATION OF AN EDUCATIONAL PROGRAM BASED ON THE MOBILE LEARNING METHODOLOGY}

\author{
Manuel Francisco Romero Oliva \\ Universidad de Cádiz, Espanha \\ manuelfrancisco.romero@uca.es \\ Rafael Jiménez Fernández \\ Universidad de Cádiz, Espanha \\ rafael.jimenezfernandez@uca.es \\ Hugo Heredia Ponce \\ Universidad de Cádiz, Espanha \\ hugo.heredia@uca.es
}

\begin{abstract}
RESUMEN: Este estudio analiza la repercusión de la metodología m-learning en los procesos de nivelación de la competencia gramatical entre estudiantes universitarios. El diseño cuasi experimental se llevó a cabo con una muestra de 128 estudiantes del Grado en Educación Primaria de la Universidad de Cádiz, distribuidos en grupo control (64 estudiantes) y experimental (64 estudiantes). El desarrollo del experimento se centró en el uso de una aplicación móvil durante siete semanas en las que se desarrollaron diversos foros virtuales para conocer la opinión de los estudiantes. La idoneidad de la aplicación se contrastó mediante un cuestionario de Technology Acceptance Model (TAM), que evidenció un alto índice de eficacia. Los resultados muestran una diferencia significativa en el proceso pretest-postest tanto entre grupos como intragrupo experimental. El estudio concluye con una matriz DAFO que sirve de referencia para una posible réplica de la implementación del programa en otros contextos.
\end{abstract}

PALABRAS CLAVE: m-learning; dispositivos móviles; competencia gramatical; formación inicial.

ABSTRACT: This study analyzes the repercussion of the m-learning methodology in the process of levelling the grammatical competence among the university students. The quasi-experimental design was carried out with a sample of 128 students of the Primary Education Degree from the University of Cádiz. These students were laid out in two groups: the first group was a control group (64 students) and the second was an experimental one (64 students). The development of the experiment was focused on the use of a mobile device application and it lasted seven weeks, in which various virtual forums emerged in order to know the opinion of the students. The suitability of the application was checked out using a Technology Acceptance Model (TAM) questionnaire, which showed a high efficiency index. The results reveal a significant difference between the pretest and the posttest process, both in the groups and in the experimental intragroup. The study concludes with a SWOT matrix that might be a support, as a reference, for a possible replication of the program's implementation in other contexts.

KEYWORDS: m-learning; mobile devices; grammatical competence; initial training. 


\section{Introducción}

El desarrollo de la competencia gramatical en los escolares exige una sólida preparación del profesorado en los contenidos gramaticales de su lengua materna. Sin embargo, la formación académica con que llegan los futuros maestros a unos estudios universitarios, que les han de habilitar para el ejercicio de su profesión docente, presenta en la actualidad importantes carencias, en particular sobre el conocimiento gramatical, que incidirán de modo negativo no solo en su futura acción didáctica en el aula, sino también en el manejo eficaz de la lengua como medio de comunicación y acceso al conocimiento científico.

Aunque la puesta en marcha del título de Grado en Educación Primaria haya contribuido decisivamente al diseño de unos planes de estudio conducentes a la adquisición de un conjunto de competencias específicas sobre formación didácticodisciplinar, lo cierto es que, en lo que se refiere al módulo de enseñanza y aprendizaje de lenguas, se ha constatado que en algunas materias dichas competencias difícilmente pueden conseguirse si las nuevas promociones de ingresados continúan acreditando una pésima formación en contenidos académicos básicos de lengua española, en especial sobre su gramática.

Consideramos que el conocimiento gramatical, lejos de debates y controversias acerca de su enseñanza en la educación obligatoria, es importante entre los usuarios de la lengua pues les capacita para la reflexión metalingüística de sus expresiones verbales. De hecho, no se concibe el desarrollo de la competencia comunicativa sin la integración en ella del componente gramatical, tal como lo indica el Consejo de Europa (2002). La importancia de disponer de un buen dominio gramatical resulta imprescindible para reflexionar conscientemente sobre los mecanismos de funcionamiento del sistema de la lengua, lo cual contribuirá a que los individuos utilicen con eficacia sus producciones lingüísticas dentro de un contexto comunicativo determinado. El saber gramatical conjuga, por un lado, la posesión de un conocimiento declarativo sobre la naturaleza y el funcionamiento de las unidades de la lengua que acerque a los individuos a su descripción y al manejo de la normativa gramatical mediante la apropiación de un metalenguaje elemental como el empleo discursivo de estas.

A partir de nuestra experiencia docente, hemos comprobado que son muchos los alumnos que cursan el Grado en Educación Primaria con un preocupante déficit sobre el conocimiento gramatical (JIMÉNEZ; ROMERO; HEREDIA, 2019). Las circunstancias no son las mismas que en décadas atrás, donde quienes aspiraban a ser maestros accedían a esta titulación con unos conocimientos lingüísticos lo suficientemente adecuados como para prestar atención educativa solo a los contenidos disciplinares de carácter didáctico. En consecuencia, siendo conscientes de la exigencia formativa de los futuros maestros en el dominio y manejo de este aspecto pues en su labor docente tendrán que llevar a cabo una transposición didáctica en el aula, nos vimos obligados a atender la actualización y mejora de su competencia gramatical conjugando en una misma materia este tipo de contenidos básicos con otros más vinculados epistemológicamente con la enseñanzaaprendizaje de la lengua.

La actualización y mejora de la competencia gramatical entre los estudiantes universitarios de magisterio es indispensable puesto que se trata de un saber lingüístico, ya abordado durante la etapa escolar obligatoria, equiparable con otros conocimientos de 
formación académica básica que debe poseer cualquier persona por cuestión de cultura general. Aparte de favorecer la reflexión explícita sobre el funcionamiento sistemático de la lengua y el empleo de un metalenguaje específico, asimismo contribuye al desarrollo de la producción textual (composición escrita), fundamentalmente en su proceso de revisión al dominio discursivo de los usos orales más elaborados, a la interiorización de las reglas ortográficas y demás aspectos normativos de la lengua, al aprendizaje gramatical de nuevas lenguas y también al desarrollo de las funciones psicológicas complejas.

\section{M-learning en la educación superior}

El vertiginoso avance de las tecnologías de la información y la comunicación (TIC) desde el inicio del siglo XXI ha comportado notables cambios científicos en todos los ámbitos de la actividad humana, entre los que destaca el campo educativo donde se ha convertido en un instrumento indispensable en la conformación de los procesos de enseñanza-aprendizaje. La evolución e innovación protagonizadas por herramientas tecnológicas digitales en la sociedad actual (ordenadores, internet, teléfonos inteligentes o smartphones, tabletas, redes sociales...) han hecho posible la elaboración, el procesamiento así como el almacenamiento, la difusión y el intercambio de datos de muy diverso tipo. Son numerosos los autores (GUTIÉRREZ MARTÍN, 2003; RODRÍGUEZ ILLERA, 2004; AGUADED; PÉREZ RODRÍGUEZ, 2006; GROS; CONTRERAS, 2006) que apuestan por una alfabetización digital dentro de una población de nativos digitales (PRENSKY, 2010/2011) que se encuentra cada vez más digitalizada y donde el empleo frecuentísimo de los dispositivos electrónicos, surgidos de los continuos cambios en el desarrollo tecnológico, ha ido reemplazando progresivamente recursos y métodos de trabajo más tradicionales. Y, esta digitalización, como hemos dicho, también se ha extendido en el ámbito educativo con tal fuerza que difícilmente pueda hallarse un espacio para la enseñanza donde el alumnado no disponga de ordenadores, móviles o tabletas para su mejora formativa.

La institución universitaria del siglo XXI no ha quedado al margen del crecimiento de las nuevas tecnologías en la sociedad. Su integración en la enseñanza superior se ha visto impulsada a partir del proceso de convergencia con el Espacio de Educación Europea Superior (EEES), que ha supuesto un significativo cambio de paradigma educativo en el que se ha aprovechado las nuevas tecnologías para la mejora de viejos planteamientos didácticos que relegaban a un segundo lugar el papel del alumnado en el proceso de enseñanza-aprendizaje. El desarrollo de la sociedad del conocimiento y la información ha determinado en la universidad la aparición de un escenario donde el aprendizaje se concibe de modo socio-constructivista.

Hoy en día no se entiende la enseñanza de lenguas sin la aportación de las nuevas tecnologías. Entre las ocho competencias clave establecidas por la Comisión Europea para el aprendizaje permanente $(2007$, p. 7) se encuentra la competencia digital, definida como "el uso seguro y crítico de las tecnologías de la sociedad de la información (TSI) para el trabajo, el ocio y la comunicación" y sustentada "en las competencias básicas en materia de TIC: el uso de ordenadores para obtener, evaluar, almacenar, producir, presentar e intercambiar información, y comunicarse y participar en redes de colaboración a través de Internet" (COMISIÓN EUROPEA, 2007, p. 7). Mediante dicha competencia el 
alumno es capaz no solo de aprovechar las enormes posibilidades didácticas de las tecnologías digitales, sino también de participar activamente en la nueva sociedad del conocimiento y la información.

El empuje transformador de las TIC exige al docente un acercamiento efectivo hacia una modalidad de aprendizaje alternativa a las tradicionales estructuras de educación de carácter presencial basada, en la mayoría de los casos, en una simple transmisión de la información y del saber académico enmarcado siempre en unos conocidos contextos espacio-temporales determinados. Más allá de estas barreras físicas de cualquier aula, existen otras dimensiones emergentes para la formación y aprendizaje del alumnado en las que se puede compartir y comunicar el conocimiento a partir de las nuevas dinámicas interactivas mediadas por las herramientas tecnológicas. Se pasa, pues, de un aprendizaje por transmisión que parte del docente a otro muy distinto, ya no condicionado por completo por el profesor, caracterizado por la interactividad del conocimiento donde el control del aprendizaje es responsabilidad del estudiante. Se trata, ciertamente, de todo un reto la incorporación de las tecnologías que afecta globalmente a todos los agentes que intervienen en el modelo didáctico aplicado en la enseñanza.

Así pues la educación superior no puede permanecer alejada de una sociedad altamente digitalizada en todos sus sectores de funcionamiento $\mathrm{y}$, por tanto, ha de valerse de las TIC como una herramienta muy eficaz, por su alto nivel de motivación, para la docencia universitaria; no obstante, pese a las elevadas expectativas que los profesores reconocen hacia las TIC y sus potencialidades pedagógicas, lo cierto es que su práctica aún no se encuentra generalizada (GUERRA; GONZÁLEZ; GARCÍA, 2010). El proceso de innovación a partir de las nuevas tecnologías digitales en su labor docente no es tarea sencilla ni se logra en poco tiempo. Es importante señalar que la planificación de actividades con tecnologías no puede realizarse de modo espontáneo, sino más bien debe partir de un modelo didáctico que las guíe. No se trata de llevar a cabo determinadas actividades con ordenadores o cualquier otro dispositivo electrónico. Muy al contrario: la cuestión radica en dotarse de esos instrumentos digitales para la consecución de unos objetivos y resultados de aprendizajes previamente planificados conforme a una metodología basada en los principios de construcción del conocimiento a través de la reflexión y del trabajo colaborativo, y que sitúa al alumno en el centro del proceso de enseñanza-aprendizaje en detrimento del papel tradicional del profesor.

En el caso del profesorado responsable de la enseñanza de lenguas, las herramientas digitales se convierten en auténticos recursos didácticos para ayudar en el aprendizaje lingüístico pues a través de ellos se puede fomentar el uso de la lengua de forma colaborativa. Si bien es verdad que la enseñanza de idiomas había ya incorporado una serie de recursos tecnológicos desde hace bastante tiempo, hemos tenido que esperar al nuevo milenio para que se produzca una extraordinaria expansión de las herramientas tecnológicas en el mundo educativo, lo cual se ha visto plasmado en numerosos trabajos e investigaciones sobre didáctica de lenguas y tecnologías en general (CARRIÓ PASTOR, 2016) y del ámbito del español como lengua extranjera (ELE) en particular (GARGIULO; GARGIULO; FERNÁNDEZ, 2015). Mención especial merece la aplicación de las redes sociales a la enseñanza de ELE, en gran auge (ERDOCIA, 2012; FERNÁNDEZ ULLOA, 2012; VARO; CUADROS, 2013; CUADROS; VILLATORO, 2014).

Con el concepto m-learning (Mobile Learning "aprendizaje móvil") (PISANT; ENRÍQUEZ; CHAOS-CADOR; GARCÍA BURGOS, 2010; HERRERA; FÉNNEMA, 2011;) 
hacemos referencia a un tipo de metodología innovadora de enseñanza-aprendizaje que utiliza pequeños dispositivos móviles (teléfonos móviles, PDA, tabletas, iPod, etc.) que poseen conectividad inalámbrica. Brazuelo y Cacheiro (2010, p. 3) lo definen como "la aplicación de los dispositivos electrónicos móviles para fines educativos". Se trata de un recurso metodológico, procedente del e-learning ${ }^{1}$, que se ha desarrollado con fuerza en los últimos años dentro de los centros escolares para realizar una forma de aprendizaje basada en la tecnología móvil como reflejo de una sociedad cada vez más cibercultural.

Como sabemos, se trata de una modalidad educativa que cuenta cada vez con mayor presencia en la educación superior al convertirse en un medio que ayuda a la construcción del conocimiento y la resolución de problemas de aprendizaje (BRAZUELO; GALLEGO, 2014).

Para Vázquez-Cano y Sevillano:

La difusión generalizada de estos dispositivos móviles ofrece una oportunidad importante para el acceso y construcción del conocimiento y puede ser una estrategia innovadora, así como una solución para responder de forma inclusiva a las diferentes necesidades de los estudiantes y sus estilos de aprendizaje (VÁZQUEZ-CANO; SEVILLANO, 2015, p. 78).

Sin embargo, el ámbito educativo nos muestra todo lo contrario, esto es, una prohibición muy extendida del uso del teléfono móvil dentro de los espacios de aprendizaje. El debate queda abierto: por un lado, quienes están convencidos de las grandes potencialidades que este dispositivo puede ofrecer gracias a sus características (COLL, 2004; WOODILL, 2011); y, por otro, los que subrayan los efectos negativos que la digitalización pudiera comportar en aula (distracciones, adicción, usos inadecuados, desfasamiento del producto, incidencias técnicas imprevistas, etc.).

Pese a la resistencia de no pocos docentes, anti-technology instructors ("profesores antitecnología") en palabras de Gikas y Grant (2013, p.23), para ayudarse del teléfono móvil como recurso didáctico, lo cierto es que no debemos ocultar algunos de los beneficios que dicho instrumento puede comportar en el aula tales como la portabilidad, la conectividad en cualquier momento y lugar, el acceso flexible a los recursos de aprendizaje, la inmediatez de la comunicación, la participación de los alumnos, el fomento de experiencias de aprendizaje significativo, el aumento de la alfabetización informática, la mejora de las competencias de comunicación y el aprendizaje colaborativo, entre otras. Asimismo, si el dispositivo móvil cuenta con acceso a la red, se suman otras ventajas: actualización de la información y de los contenidos, deslocalización del conocimiento, autonomía del estudiante, formación multimedia, formación grupal y colaborativa, registro en los servidores de la actividad realizada por los estudiantes, etc. (CABERO, 2006). Como vemos, se trata de ventajas derivadas de las características físicas y operativas del dispositivo en sí a las que se les suman otras potencialidades de tipo didáctico pues contribuyen significativamente a la adquisición, actualización o refuerzo de determinados contenidos de asignaturas.

1 Entendemos e-learning como aprendizaje en red. A partir de este término, han surgido otra serie de términos relacionados, aparte del que abordamos aquí, tales como b-learning (modalidad semipresencial de estudios que incluye tanto la formación no presencial como la presencial), t-learning (aprendizaje a través de la televisión), u-learning ("aprendizaje ubicuo"), referido al aprendizaje a través de la tecnología, que se puede realizar en cualquier momento y lugar. 
En este sentido, estamos ante una herramienta de la que disponen prácticamente todos los estudiantes, que sirve tanto para el profesor como para estos, sobre todo, para afrontar interactivamente aquellos aprendizajes donde se detectan mayores problemas.

Podemos afirmar, pues, que el m-learning es una innovación metodológica que consiste en el aprendizaje móvil; no obstante, la utilización del teléfono móvil en el aula no constituye per se una innovación, sino que depende más bien del modo en que llegue a emplearse (COLL, 2004; IMBERNÓN, 2006; MARTÍNEZ SÁNCHEZ, 2006). Por ello, la formación del profesorado se convierte en un elemento esencial para el cambio orientado a la mejora de los procesos educativos mediante las TIC.

Entre las muchas potencialidades funcionales de los teléfonos móviles inteligentes (conocidos también como smartphones) está la de poder trabajar con aplicaciones móviles (apps en inglés) a partir de un software descargable destinado a la ejecución de una determinada tarea, en nuestro caso, encaminada a la consecución de unos objetivos didácticos determinados. Según indican Winer y Vázquez (2002, p. 9) "para que un software, pueda ser calificado de educativo, tiene que haber sido diseñado didácticamente, pensando en el proceso de aprendizaje". Se trata de recursos muy motivadores que despiertan el interés entre los estudiantes, nativos digitales, les ayudan fundamentalmente en las modalidades de aprendizaje a distancia y autónomo, y con una presencia cada vez mayor en universidades tradicionalmente ligadas a una metodología didáctica presencial.

El uso de aplicaciones supone un gran potencial didáctico y motivador para la enseñanza de la lengua, en consonancia con la recomendación del Instituto Cervantes (2012, p. 27) de "desenvolverse en entornos digitales y con aplicaciones informáticas disponibles". A través de ellas los alumnos se convierten en protagonista de la construcción de su proceso de aprendizaje, lejos de estrategias metodológicas de carácter transmisivo.

En este trabajo presentamos los resultados que hemos obtenido después de utilizar una aplicación móvil (eLearning Morfosintaxis) como apoyo al proceso de enseñanzaaprendizaje para la nivelación de contenidos gramaticales incluidos en una asignatura universitaria de Grado².

\section{Objetivos y metodología}

Esta investigación pretende afrontar las dificultades referidas a la competencia gramatical que los estudiantes ofrecen en su primer curso de acceso Grado en Educación Primaria. Encuadrada en un diseño de investigación evaluativa, de tipo cuasi experimental pre-postest con grupo control (CAMPBELL; STANLEY, 1966), analiza la repercusión de un programa educativo basado en el uso de aplicaciones móviles (m-learning).

Para ello, se opta por una metodología mixta de corte interpretativo en la que el investigador se convierte en el principal activo en la recogida de datos (COLÁS, 1998), mediante diversas técnicas e instrumentos vinculados a unos objetivos específicos que contribuirán a la comprensión de la situación (SANDíN, 2003):

2 Esta investigación se encuadra en la transferencia de resultados de un proyecto de invocación docente Blended Learning: E/ALAO como estrategia de autonivelación para la competencia gramatical en estudiantes de grado de magisterio y MAES, correspondiente a las Actuaciones Avaladas para la Mejora Docente de la Universidad de Cádiz. 
- Objetivo 1: Analizar la implementación del uso de una aplicación móvil (app) en el proceso de nivelación de la competencia gramatical en estudiantes del Grado en Educación Primaria.

- Objetivo 2: Conocer el pensamiento de los estudiantes del Grado en Educación Primaria sobre la metodología m-learning en el proceso de nivelación de su competencia gramatical.

- Objetivo 3: Determinar las debilidades y las fortalezas así como las amenazas y oportunidades en la formación inicial docente a través de una matriz DAFO, tomando como referencia a los estudiantes del Grado en Educación Primaria, sobre el proceso de nivelación basado en la metodología m-learning.

\title{
3.1 Contexto y participantes
}

Esta investigación se realizó en el marco de los estudios de Grado en Educación Primaria de la Universidad de Cádiz en la asignatura de primer curso Didáctica de la Lengua Materna, que incluye una competencia básica (CB1) vinculada a

\begin{abstract}
que los estudiantes hayan demostrado poseer y comprender conocimientos en un área de estudio que parte de la base de la educación secundaria general, y se suele encontrar a un nivel que, si bien se apoya en libros de texto avanzados, incluye también algunos aspectos que implican conocimientos procedentes de la vanguardia de su campo de estudio (CB1).
\end{abstract}

que se corresponde con el bloque de contenidos de la asignatura " 5 . Actualización en contenidos gramaticales y léxico-semánticos básicos." (Bloque 5), en el que se desarrollan aspectos gramaticales en el ámbito de la morfología y de la sintaxis; siendo el resultado de aprendizaje esperado "Acreditar una competencia gramatical conforme a un nivel básico preuniversitario".

La muestra de estudio se compone de 128 estudiantes de primer curso del Grado en Educación Primaria y pertenecen a dos grupos clase que fueron seleccionados por cuestiones de accesibilidad y seguimiento del experimento, al ser los investigadores los docentes responsables de esta asignatura. En la distribución de los estudios de procedencia - Tabla 1 -, se observa que alrededor del $18 \%$ de los estudiantes no acceden desde los estudios de Bachillerato, aspecto que conlleva una mayor diversidad competencial en el dominio de los aspectos gramaticales.

\subsection{Diseño de la investigación}

El paradigma de estudio se corresponde con un método mixto: dentro de la metodología cuantitativa, se trata de una investigación cuasi experimental - Tabla 1 -, que pretende analizar en qué medida repercute la implementación de un experimento $(X)$ en un grupo de estudiantes - considerado experimental - mediante una metodología basada en el uso de una aplicación móvil (m-learning), frente a otro grupo estático respecto al diseño de implementación - denominado control - que mantendrá la cultura de aprendizaje durante el experimento: 
Tabla 1: Diseño de investigación cuasi experimental.

\begin{tabular}{|l|c|c|c|}
\hline \multicolumn{1}{|c|}{ Diseño } & Pretest & Experimento & Postest \\
\hline Grupo experimental & $\mathrm{t}_{1}$ & $\mathrm{X}$ & $\mathrm{t}_{2}$ \\
\hline Grupo control & $\mathrm{t}_{1}$ & - & $\mathrm{t}_{2}$ \\
\hline
\end{tabular}

Además, no podemos olvidar los diversos estudios de procedencia desde los que acceden a la educación superior - Tabla 2. Consideramos que esta investigación puede contribuir a afrontar la diversidad de niveles de dominio vinculados a los estudios conducentes y que, ante la falta de tiempo para afrontarla por los contenidos de las materias, se convierte en un problema en la formación inicial de los maestros de cara a su futura práctica docente. Es de ahí de donde parte nuestra hipótesis: el uso de artefactos digitales integrados en los procesos de enseñanza-aprendizaje -móviles y app- ofrece una oportunidad de nivelación gramatical desde una metodología autónoma entre los estudiantes de educación superior:

Tabla 2: Distribución de grupos control y experimental según procedencia de estudios.

\begin{tabular}{|c|c|c|c|c|c|c|}
\hline Procedencia & \multicolumn{2}{|c|}{ Bachillerato } & \multicolumn{2}{c|}{ Ciclo Superior } & \multicolumn{2}{c|}{ Universidad } \\
\hline Grupos & $\mathbf{n}$ & $\mathbf{\%}$ & $\mathbf{n}$ & $\%$ & $\mathbf{n}$ & $\%$ \\
\hline Experimental & 55 & 85,9 & 7 & 10,9 & 2 & 3,1 \\
\hline Control & 52 & 81,3 & 7 & 10,9 & 5 & 7,8 \\
\hline Total & 107 & 83,6 & 14 & 10,9 & 7 & 5,5 \\
\hline
\end{tabular}

Por otro lado, dentro de la investigación cualitativa - Tabla 3 -, durante el proceso de implementación y tras el experimento, se pretendió describir y analizar la voz de los estudiantes desde la etnografía educativa y la investigación de diseño al incorporar sus "conductas sociales colectivas e individuales, las opiniones, los pensamientos y las percepciones" (MCMILLAN; SCHUMACHER, 2006, p. 400); de manera que se pudiera dilucidar la adecuación del método y la idoneidad de la aplicación (app).

De esta forma, como investigación mixta, se decidió incorporar técnicas de diversos métodos - Tabla 3:

Tabla 3: Métodos, técnicas e instrumentos de la investigación.

\begin{tabular}{|l|c|l|l|}
\hline \multicolumn{1}{|c|}{ Métodos } & Objetivos & \multicolumn{1}{c|}{ Técnicas } & \multicolumn{1}{|c|}{ Instrumentos } \\
\hline a) Cuasi experimental & 1 & Análisis competencial $\left(\mathrm{t}_{1}-\mathrm{t}_{2}\right)$ & Cuestionario \\
\hline \multirow{2}{*}{ b) Etnografía educativa } & 2 & TAM & Cuestionario \\
\cline { 2 - 5 } & 2 & Foro virtual educativo & $\begin{array}{l}\text { Cuestionario } \\
\text { semiestructurado }\end{array}$ \\
\hline c) Investigación de diseño & 3 & Categorización & Matriz DAFO \\
\hline
\end{tabular}

La inclusión de los métodos y técnicas empleados se justifica desde las siguientes actuaciones desarrolladas en esta investigación:

a) El diseño cuasi experimental (CAMPBELL; STANLEY, 1968): los resultados de la investigación no solo se centrarán en una evaluación sumativa de la competencia 
gramatical en el grupo experimental $\left(t_{1}-x-t_{2}\right)$; sino que, además, se llevará a cabo un contraste de significatividad entre ambos grupos de estudio $\left(t_{2}-t_{2}\right)$, analizando aspectos referidos a la eficacia de la metodología m-learning y el uso de la aplicación móvil.

b) Desde la etnografía educativa, mediante la creación de un foro educativo y un cuestionario Technology Acceptance Model (TAM), se dio voz a los auténticos destinatarios de la investigación: los estudiantes. Así, se indagó en el empleo de la aplicación móvil y en la metodología de trabajo para "describir las diversas perspectivas y actividades de profesores y alumnos con el fin de obtener explicaciones para descubrir patrones de comportamiento" (LATORRE; DEL RINCÓN; ARNAL, 2005, p.226).

c) Finalmente, la Educational Design Research ("investigación de diseño") aglutinaba todas las estrategias de indagación para "comprender y mejorar la realidad educativa a través de la consideración de contextos naturales en toda su complejidad y del desarrollo y análisis paralelo de un diseño instruccional específico" (MOLINA; CASTRO; MOLINA; CASTRO, 2011, p. 75), y tuvo como resultado la realización de una matriz DAFO.

\subsection{Descripción de los instrumentos de la investigación}

\subsubsection{Cuestionario de dominio gramatical}

Esta prueba está formada por 20 ejercicios - Anexo 1 - que analizan la competencia gramatical desde dos ámbitos lingüísticos: morfología (ítems 1 a 9) y sintaxis (ítems 10 a 20). Cada ítem fue valorado con un criterio de escala nominal en la que se categorizaron tres etiquetas: (2) acierto en la respuesta, (1) error en la respuesta, (0) sin respuesta. En el análisis de la tasa de éxito se consideró el valor 2, frente a los valores 1 y 0 , que fueron agrupados como tasas de error.

Puesto que se realizaron dos pruebas para evaluar la influencia de la metodología implementada en el desarrollo de la competencia gramatical (pretest y postest), cada ítem del cuestionario - Anexo 1 - aparece especificado con aquellos ejercicios de cada momento del diagnóstico.

El análisis cuantitativo de los datos se efectuó mediante el paquete informático Startical Product and Service Solution (SPSS), versión 22.

\subsubsection{Cuestionario semiestructurado en foro educativo}

Abogamos en este apartado por el concepto de escritura de la experiencia (CONTRERAS, 2010), en donde escribir permite fijar lo vivido y "poner en relación lo que ha sido vivido con lo que ello nos hace pensar; o lo que ha sido sentido con la capacidad de captarlo; o lo que ha ocurrido con aquello que nos interpela sobre el hacer educativo" (SIERRA; CAPARRÓS; MOLINA; BLANCO, 2017, p. 677). Al considerar que era preciso evaluar el proceso de implementación del experimento, se creó un foro virtual que sirviera para recoger la experiencia de los estudiantes desde la reflexión vivida y ofrecieran su visión -Tabla 4- sobre esta metodología no solo desde su propio aprendizaje, sino desde 
la propia acción del futuro docente.

Tabla 4: Creencias y concepciones del programa implementado.

\begin{tabular}{|c|l|}
\hline Bloques temáticos & \multicolumn{1}{c|}{ Tópicos generadores } \\
\hline Aplicación móvil & $\begin{array}{l}\text { ¿Consideras la aplicación una estrategia adecuada para trabajar de manera } \\
\text { autónoma? } \\
\text { Aspectos positivos y de mejora de la aplicación }\end{array}$ \\
\hline Formación & $\begin{array}{l}\text { ¿Qué te ha aportado para afrontar la asignatura? } \\
\text { ¿Qué te ha aportado para nivelarte en tu competencia gramatical? } \\
\text { ¿Consideras una opción metodológica para llevarla al aula como docente? }\end{array}$ \\
\hline
\end{tabular}

Los participantes del grupo experimental dispusieron del foro en el campus virtual de la asignatura para que fueran compartiendo su experiencia. El análisis cualitativo de sus intervenciones se llevó a cabo con el software NVivo 11.

\subsubsection{Cuestionario TAM}

El Modelo de Aceptación Tecnológica (TAM) se presenta como una herramienta para averiguar la percepción de los usuarios de una tecnología respecto a su uso y utilidad. Cimentada en la Theory of Reasoned Action ("Teoría de la Acción Razonada", TRA) (AJZEN; FISHBEIN, 1980), es Davis (1989) el que centra el análisis en dos factores: utilidad percibida (PU) y de percepción de facilidad de uso (PEOU). En este sentido, Cuesta, Abella y Alegre (2014) delimitan las variables para analizar la aceptación tecnológica de una aplicación, siendo concretadas, en nuestra investigación, en tres dimensiones: utilidad de la aplicación, su facilidad de uso y motivación - Tabla 5 -, y 10 preguntas específicas de valoración dicotómica (sí/no) en la respuesta de los estudiantes.

Tabla 5: Cuestionario TAM: dimensiones e ítems.

\begin{tabular}{|c|c|l|}
\hline Dimensiones sobre la aplicación & Ítem & \multicolumn{1}{|c|}{ Pregunta } \\
\hline \multirow{4}{*}{ Utilidad de la aplicación } & 1 & $\begin{array}{l}\text { ¿La aplicación te ha resultado útil para mejorar tu dominio de la } \\
\text { gramática? }\end{array}$ \\
\cline { 2 - 4 } & 2 & $\begin{array}{l}\text { ¿La aplicación te ha servido para adquirir técnicas útiles para } \\
\text { enseñar gramática? }\end{array}$ \\
\cline { 2 - 4 } & 3 & ¿Ha sido útil la teoría que aparece? \\
\hline \multirow{4}{*}{ Facilidad de uso } & 4 & $\begin{array}{l}\text { ¿La metodología de la aplicación te ha parecido intuitiva para } \\
\text { aprender gramática? }\end{array}$ \\
\cline { 2 - 4 } & 5 & ¿El diseño de la aplicación te ha facilitado el uso? \\
\cline { 2 - 4 } & 6 & ¿La aplicación te ha servido para trabajar de forma autónoma? \\
\hline \multirow{5}{*}{ Motivación de uso } & 7 & $\begin{array}{l}\text { ¿Has utilizado el foro con frecuencia para compartir el uso de la } \\
\text { aplicación? }\end{array}$ \\
\cline { 2 - 3 } & 8 & ¿Te ha motivado para trabajar la gramática? \\
\cline { 2 - 3 } & 9 & ¿Utilizarías esta aplicación en tu futura labor como docente? \\
\cline { 2 - 3 } & 10 & $\begin{array}{l}\text { ¿Usarías la aplicación para continuar aprendiendo fuera del } \\
\text { aula? }\end{array}$ \\
\hline
\end{tabular}


El análisis cuantitativo de los datos se efectuó mediante el paquete informático Startical Product and Service Solution (SPSS), versión 22.

\subsubsection{Realización de una matriz DAFO}

Los testimonios de los estudiantes - foro educativo y TAM - y su confrontación con otras investigaciones consultadas sirvieron para la elaboración de una matriz DAFO que sintetizara las causas internas (debilidades y fortalezas) y externas (amenazas y oportunidades) - Tabla 6. Este punto de referencia puede servir de apoyo para replicar en otros contextos el programa implementado y diseñar estrategias para afrontar la problemática de los bajos niveles competenciales de los estudiantes de magisterio de cara a su formación inicial.

Tabla 6: Dimensión 5. Matriz DAFO.

\begin{tabular}{|c|c|}
\hline Análisis de las causas internas & Análisis de las causas externas \\
\hline Debilidades & Amenazas \\
\hline & Oportunidades \\
\hline Fortalezas & \\
\hline & \\
\hline
\end{tabular}

\section{Desarrollo del programa y resultados}

\subsection{El pretest: diagnóstico de la competencia gramatical de los estudiantes}

La prueba inicial realizada a los dos grupos de estudio sirvió para elegir la opción más adecuada sobre la que implementar el experimento - metodología m-learning y uso de la aplicación móvil. La media obtenida en el cuestionario de competencia gramatical en el pretest - Anexo 1 - ofreció resultados similares en ambos grupos. Tomada la opción dicotómica (acierto-error) en la que el valor 2 del intervalo se corresponde con el acierto en la respuesta y el valor 1 , con el error; la media de la prueba ofrece un resultado global de 1,4682. Respecto a la actuación metalingüística del grupo experimental - Figura 1 -, tanto en morfología $(1,4679)$ como en sintaxis $(1,4006)$, la media es inferior a la ofrecida por el grupo control. Este dato justifica la elección del grupo experimental ya que su nivel competencial ofrecía resultados más bajos y justificaba la implementación de la metodología para la autonivelación. 




Figura 1: Pretest. Descriptivos según variable actuación metalingüística.

La distribución de las respuestas en ambos grupos evidenció una falta de dominio en las actuaciones metalingüísticas: en el ámbito de la morfología - ítems 1 a 9 -, solamente los ítems 1 y I 2 ofrecen una tasa de éxito superior al 50\%, llegándose a registrar resultados inferiores al $20 \%$ en tres - números 5,7 y 8 . Por otro lado, la actuación en el ámbito de la sintaxis presenta datos superiores - ítems 9 a 20; sin embargo, la existencia de ítems con porcentajes muy bajos no desaparece, como es el caso del ítem 12. En este sentido, podemos considerar que tanto el grupo control como el experimental mostraron irregularidad en el dominio de la morfología y la sintaxis y que, como se observa en el gráfico radial - Figura 2 -, el nivel de éxito no llegó a superar el $80 \%$, salvo de manera puntual en el grupo experimental: una, en morfología - ítem 2 - y otra, en sintaxis - ítem 11. 


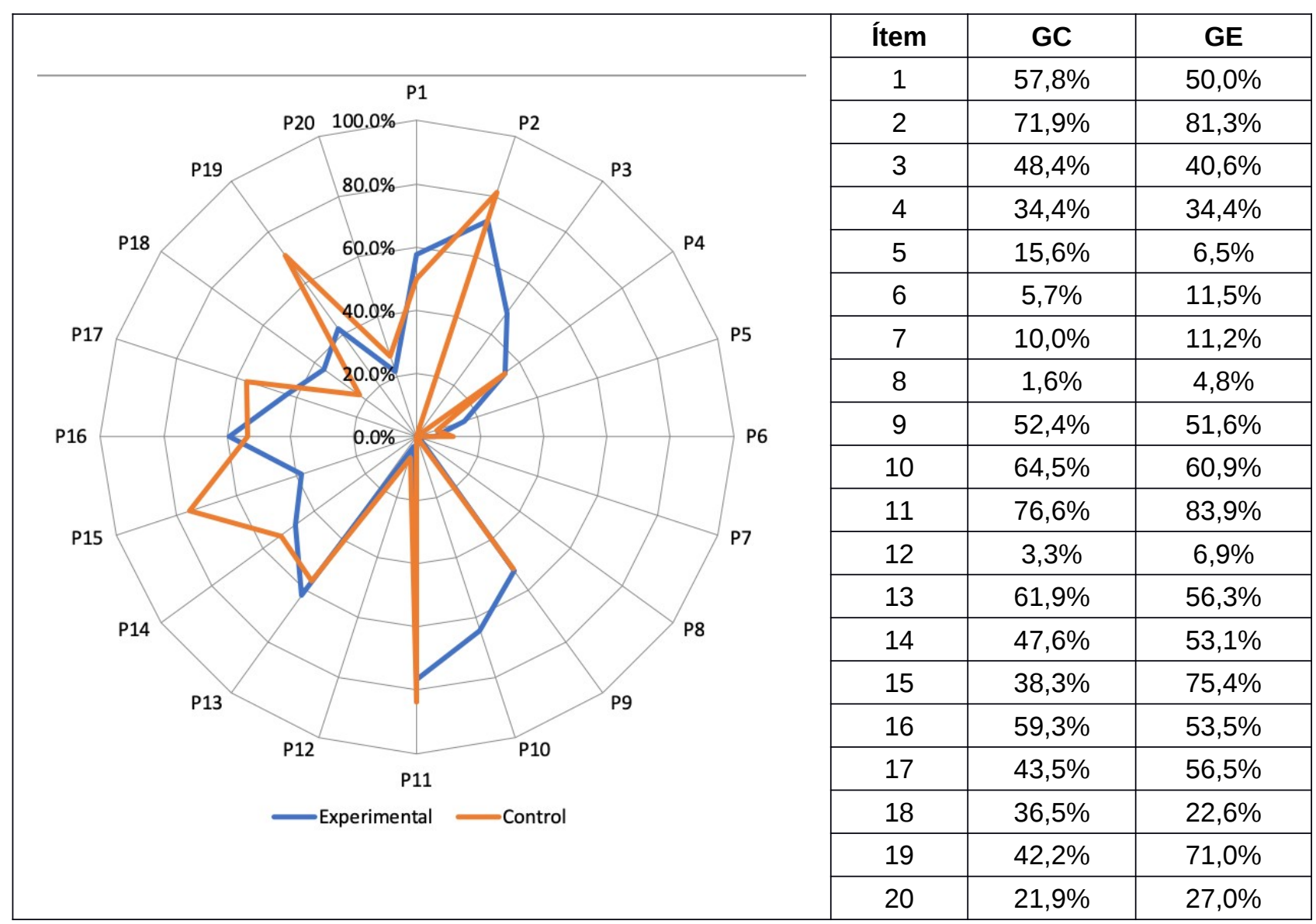

Figura 2: Pretest. Tasas de éxito porcentual del grupo control y del grupo experimental.

Otro aspecto que justificó la necesidad de nivelación en la competencia gramatical fue la diversidad que suele encontrarse en las aulas como consecuencia de los estudios conducentes a los grados universitarios - Tabla 7. En nuestro caso, los estudiantes proceden en su mayoría de bachillerato (inicialmente con una formación en el análisis de la lengua que han debido demostrar tanto en los estudios de educación secundaria como bachillerato y en la prueba de acceso a la universidad). No obstante, los estudios de grado superior también dan acceso al grado de magisterio y su formación lingüística no se contempla en esa modalidad, lo que conlleva una situación de desventaja para afrontar la formación disciplinar en didáctica de la lengua. Como se observa en la tabla 7, la media en las tasas de éxito de ciclo superior $(29,5 \%)$ muestra un resultado muy inferior a los estudiantes de bachillerato $(42,7 \%)$ o de otros estudios universitarios $(42,3 \%)$. 
Tabla 7: Pretest. Tasas de éxitos porcentuales de dominio gramatical por estudio de procedencia.

\begin{tabular}{|c|c|c|c|c|c|c|}
\hline \multirow{3}{*}{ Ámbito lingüístico } & \multirow{3}{*}{ Ítem } & \multirow{2}{*}{\multicolumn{2}{|c|}{$\begin{array}{c}\text { Bachillerato } \\
\text { Tasas de éxito (\%) }\end{array}$}} & \multirow{2}{*}{\multicolumn{2}{|c|}{$\begin{array}{c}\text { Ciclo superior } \\
\text { Tasas de éxito (\%) }\end{array}$}} & \multirow{3}{*}{\begin{tabular}{|c|} 
Universidad \\
Tasas de éxito (\%) \\
Control
\end{tabular}} \\
\hline & & & & & & \\
\hline & & Control & Experim. & Control & Experim. & \\
\hline \multirow{9}{*}{ Morfología } & 1 & 51,9 & 60,0 & 14,3 & 42,9 & 80,0 \\
\hline & 2 & 80,8 & 72,7 & 71,4 & 71,4 & 100 \\
\hline & 3 & 46,2 & 49,1 & 28,6 & 42,9 & 0,0 \\
\hline & 4 & 30,8 & 38,2 & 42,9 & 0,0 & 60,0 \\
\hline & 5 & 8,0 & 14,5 & 0,0 & 14,3 & 0,0 \\
\hline & 6 & 10,2 & 4,3 & 14,3 & 0,0 & 20,0 \\
\hline & 7 & 11,8 & 7,7 & 0,0 & 33,3 & 20,0 \\
\hline & 8 & 6,0 & 1,9 & 0,0 & 0,0 & 0,0 \\
\hline & 9 & 55,8 & 56,4 & 28,6 & 33,3 & 40,0 \\
\hline \multirow{11}{*}{ Sintaxis } & 10 & 61,5 & 67,9 & 42,9 & 28,6 & 80,0 \\
\hline & 11 & 88,0 & 76,4 & 71,4 & 71,4 & 60,0 \\
\hline & 12 & 8,3 & 3,8 & 0,0 & 0,0 & 0,0 \\
\hline & 13 & 57,7 & 63,6 & 42,9 & 33,3 & 60,0 \\
\hline & 14 & 53,8 & 49,1 & 28,6 & 33,3 & 80,0 \\
\hline & 15 & 78,0 & 40,4 & 50,0 & 33,3 & 80,0 \\
\hline & 16 & 53,3 & 59,6 & 50,0 & 60,0 & 60,0 \\
\hline & 17 & 56,9 & 45,3 & 33,3 & 42,9 & 80,0 \\
\hline & 18 & 25,5 & 40,7 & 14,3 & 14,3 & 0,0 \\
\hline & 19 & 72,5 & 45,5 & 66,7 & 14,3 & 60,0 \\
\hline & 20 & 33,3 & 23,6 & 0,0 & 14,3 & 0,0 \\
\hline & Total & 44,5 & 41,0 & 30,0 & 29,2 & 44 \\
\hline
\end{tabular}

Tras el diagnóstico inicial, podemos asegurar que ninguno de los grupos de estudio presentó un dominio adecuado para ejercer la función de mediador docente en el aula de educación primaria. Este hecho, unido al diseño de los temarios de las asignaturas en el que no cabe la posibilidad de incorporar contenidos que ya se suponen adquiridos en sus estudios anteriores, justifica el diseño de un experimento basado en una metodología activa - como es m-learning y el uso de aplicaciones móviles (HINOJO; AZNAR; ROMERO, 2018), para afrontar el reto de la nivelación lingüística en la formación inicial de maestros.

\subsection{Implementación de la metodología m-learning}

La implementación del experimento tuvo una duración de siete semanas en el desarrollo de la asignatura - Tabla 8. Tras haberse realizado el diagnóstico, en el grupo experimental se explicó la metodología que se iba a desarrollar - m-learning - basada en el uso de una aplicación móvil - Figura 1 - y la creación de un foro virtual, en el que el docente actuaba de mediador ante las dudas que iban surgiendo. El plan de actuación 
consistió:

- El primer día se explicó la dinámica de trabajo y la aplicación móvil. Solo podían registrarse en el sistema operativo móvil Android, desarrollado por Google.

- Durante las siete semanas del experimento, en las clases de grupos prácticos se utilizaba la aplicación: primero, se explicaba el contenido y luego, los 15 minutos últimos se dejaba tiempo para trabajar con la aplicación. Aquellos alumnos que no tenían aplicaciones con sistema operativo Android se ponían en pareja con otro compañero.

- Durante el proceso, a través del foro virtual de la asignatura, los estudiantes fueron comentando aquellos aspectos positivos e ideas de mejoras tanto de la aplicación móvil como de la metodología de trabajo.

Tabla 8: Sesiones de implementación del programa con la app.

\begin{tabular}{|c|c|c|}
\hline Sesiones & Contenidos & Tópicos tratados en el foro \\
\hline Semana 1 & Sustantivo-Adjetivo calificativo & \multirow{7}{*}{$\begin{array}{l}\text { - ¿Qué te ha aportado la sesión para afrontar la } \\
\text { asignatura? } \\
\text { - ¿Qué te ha aportado para nivelarte en tu } \\
\text { competencia gramatical? } \\
\text { - ¿Consideras la aplicación una estrategia } \\
\text { adecuada para trabajar de manera autónoma? } \\
\text { - Aspectos positivos y de mejora de la aplicación }\end{array}$} \\
\hline Semana 2 & Adjetivo determinativo- pronombres & \\
\hline Semana 3 & Verbos & \\
\hline Semana 4 & $\begin{array}{c}\text { Adverbios, preposiciones y } \\
\text { conjunciones }\end{array}$ & \\
\hline Semana 5 & Funciones sintácticas & \\
\hline Semana 6 & Oración simple & \\
\hline Semana 7 & Oración compuesta & \\
\hline
\end{tabular}

Dentro del plan de trabajo, el diseño de la aplicación - Figura 3 - fue desarrollado en el marco de una Actuación Avalada para la Mejora Docente de la Universidad de Cádiz, Blended Learning: E/ALAO como estrategia de autonivelación para la competencia gramatical en estudiantes de grado de magisterio y MAES. El objetivo principal estuvo centrado en que los estudiantes pudieran repasar la teoría de todas las categorías gramaticales y realizar ejercicios para afianzar los conocimientos de morfología y sintaxis. Los ejercicios se plantearon para que posibilitaran la autoevaluación ya que el estudiante podía comprobar y reflexionar sus errores metalingüísticamente al aparecer un diálogo donde se especificaba su fallo. Finalmente, la aplicación ofrecía la opción de realizar ejercicios donde se combinaban las diferentes clases gramaticales. 




Figura 3: Diseño de la aplicación eLearning Morfosintaxis.

Fuente: Captura de pantalla del enlace de la aplicación

https://androidappsapk.co/detail-elearning-com-elearning/com.elearning/

Dentro de los objetivos de la investigación, se consideró necesario analizar la validez y adecuación del instrumento clave del experimento, la aplicación móvil. Para ello, se diseñó un cuestionario TAM - Tabla 9 - que indagara en la idea de conocer si la tecnología había sido utilizada de manera óptima desde el análisis de tres dimensiones: utilidad $(82,8 \%$ de éxito de valoración), facilidad $(84,8 \%)$ y motivación de uso $(73,4 \%)$.

Tabla 9: Resultados del cuestionario TAM por dimensiones e ítems.

\begin{tabular}{|c|c|c|c|c|}
\hline Dimensiones & Ítem & Pregunta & sí & NO \\
\hline \multirow{3}{*}{$\begin{array}{l}\text { Utilidad de la } \\
\text { aplicación }\end{array}$} & 1 & ¿La aplicación te ha resultado útil para mejorar tu dominio de la gramática? & $87,9 \%$ & $12,1 \%$ \\
\hline & 2 & $\begin{array}{l}\text { ¿La aplicación te ha servido para adquirir técnicas útiles para } \\
\text { enseñar gramática? }\end{array}$ & $75,8 \%$ & $24,2 \%$ \\
\hline & 3 & ¿Ha sido útil la teoría que aparece? & $84,8 \%$ & $15,2 \%$ \\
\hline \multirow{3}{*}{$\begin{array}{l}\text { Facilidad de } \\
\text { uso }\end{array}$} & 4 & $\begin{array}{l}\text { ¿La metodología de la aplicación te ha parecido intuitiva para } \\
\text { aprender gramática? }\end{array}$ & $78,8 \%$ & $21,2 \%$ \\
\hline & 5 & ¿El diseño de la aplicación te ha facilitado el uso? & $84,8 \%$ & $15,2 \%$ \\
\hline & 6 & ¿La aplicación te ha servido para trabajar de forma autónoma? & $90,9 \%$ & $9.1 \%$ \\
\hline \multirow{4}{*}{$\begin{array}{l}\text { Motivación } \\
\text { de uso }\end{array}$} & 7 & ¿Has utilizado el foro con frecuencia para compartir el uso de la aplicación? & $72,2 \%$ & $27,3 \%$ \\
\hline & 8 & ¿Te ha motivado para trabajar la gramática? & $69,7 \%$ & $30,3 \%$ \\
\hline & 9 & ¿Utilizarías esta aplicación en tu futura labor como docente? & $78,8 \%$ & $21,2 \%$ \\
\hline & 10 & ¿Usarías la aplicación para continuar aprendiendo fuera del aula? & $72,7 \%$ & $27,3 \%$ \\
\hline \multicolumn{3}{|r|}{ Media } & $79,6 \%$ & $20,4 \%$ \\
\hline
\end{tabular}


Los resultados del TAM fueron muy positivos pues mostraron una influencia elevada de la aplicación en el proceso de nivelación gramatical en los estudiantes del grupo experimental con una valoración global del $79,6 \%$ en relación con la metodología de trabajo y el empleo de la app. Destacan aquellas preguntas que se refieren a la dimensión de facilidad de uso - tanto en la intuición $(78,8 \%)$ como en la posibilidad de trabajar de manera autónoma $(90,9 \%)$-, ya que evidencian su idoneidad para este tipo de metodologías activas e-learning, en las que el estudiante adquiere un mayor protagonismo. En este sentido, la motivación se convierte en un elemento complementario que también arrojó unos porcentajes elevados, sobre todo, en indicadores como el meta aprendizaje - un 78,8\% emplearía la aplicación en un futuro como docentes - o le serviría para el desarrollo de la formación continua fuera del aula (72,7\%). Ambos indicadores se complementan con la utilidad para afrontar con éxito la nivelación gramatical. Así, la teoría incluida $(84,8 \%)$ y su adecuación para el aprendizaje gramatical $(87,9 \%)$ confirman la aceptación tecnológica de esta aplicación en el aprendizaje de la gramática.

La exploración de las concepciones que los estudiantes incluyeron en el foro virtual durante las siete semanas del experimento - Tabla 8 - serviría para confeccionar una visión más amplia y certera de la experiencia educativa. El análisis del discurso de los participantes, a partir de nodos de conglomerados por similitud de las tres dimensiones del TAM - Figura 4 -, muestran una correlación entre sí de relaciones perfectas entre los tres vértices de estudio: facilidad-utilidad-motivación de uso de la aplicación.

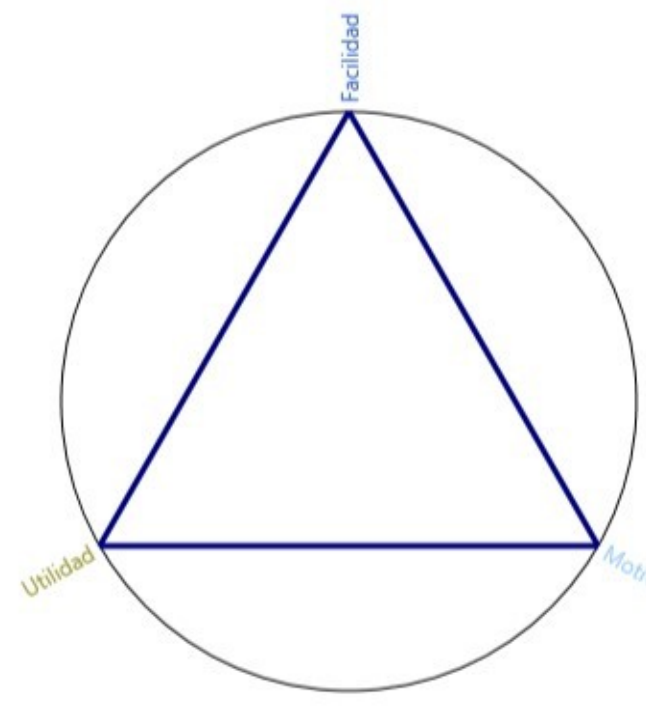

Figura 4: Nodos conglomerados por similitud codificación.

Una visión que viene reforzada al comprobarse que la serie de nodos de correlación por conglomerados - Tabla 10 - presenta un índice con valor máximo en el coeficiente de Jaccard, distribuyendo la similitud entre dos nodos o conjunto de elementos (entre 0 , como valor mínimo, y 1, como máxima similitud). De esta forma, se contempla la relevancia de planificar metodologías de enseñanza en las que la facilidad de uso de una aplicación móvil conlleva a la motivación del aprendiz que concibe la utilidad de lo que 
está aprendiendo de manera autónoma y activa.

Tabla 10: Nodos de correlación por conglomerados.

\begin{tabular}{|c|c|c|}
\hline Nodo A & Nodo B & Coeficiente de Jaccard \\
\hline Motivación & Facilidad & 1 \\
\hline Utilidad & Facilidad & 1 \\
\hline Utilidad & Motivación & 1 \\
\hline
\end{tabular}

Así, este análisis se amplió con preguntas, a modo de input o tópico motivador, que se plantearon en el foro virtual educativo - Tabla 8. Estas ofrecieron una imagen vinculada a la concepción de los estudiantes respecto a la metodología e-learning y la aplicación móvil. Su visión de pertenencia al grupo evidenció una situación de aprendizaje compartida en las diversas dimensiones analizadas en el TAM. Como referencia de acceso y facilidad del manejo de la aplicación, el comentario de que "la aplicación presenta una interfaz muy limpia y ordenada, es fácil de usar y facilita bastante el estudio de lo que se desarrolla en las clases" (GExp ${ }^{3}$-02) es constante entre los mensajes del foro; lo que manifiesta un empleo intuitivo: "me parece una aplicación bastante eficaz ya que nos atrae más debido a que se puede hacer a través de la tecnología de una forma más rápida y sencilla" (GExp_17). Sin embargo, el aspecto más repetido entre los comentarios de los estudiantes se refiere a la autonomía y facilidad de uso: "Como dicen mis compañeros, es una aplicación muy útil para recordar los términos que hemos visto en clase y poder repasarlos día a día y no dejarlo para justo antes del examen y una manera muy práctica de conseguir que los repasemos de manera autónoma" (GExp_11).

Por otro lado, consideramos que método y herramienta poco aportarían al proceso de aprendizaje si estos elementos no fueran valorados desde la utilidad de la aplicación con el objetivo de la nivelación gramatical. En este sentido, los estudiantes consideraron, como aparece en el siguiente testimonio, que

[...] aunque desconocía totalmente la aplicación me ha parecido un método moderno y sencillo de practicar lo aprendido en clase. Es una forma sencilla de entender la teoría y llevarla a cabo en sus cortos ejemplos que son corregidos al instante. En mi opinión, la aplicación es una buena forma de trabajar de manera autónoma, ya que es rápida y fácil de usar, puedes hacer muchos ejercicios y repetir cada uno de ellos las veces que veas oportunas (GExp_39)

Y, de esta forma, aparece la idea de autoformación "en relación con mi competencia gramatical me aporta la seguridad de comprobar si tengo claros los conocimientos y conceptos con los que estoy trabajando" (GExp_27), y "puedo conocer otros métodos de aprendizaje, además de ser un camino más fácil y dinámico para llegar al conocimiento" (GExp_55) y "poder hacer un balance crítico sobre mi competencia gramatical" (GExp_48).

Finalmente, la motivación se produjo desde la cohesión de aspectos cotidianos, como son los teléfonos móviles, con el acceso al conocimiento gramatical:

3 Los testimonios de informantes vienen categorizados indicando el grupo de pertenencia -grupo experimental, GExp- seguido de guion bajo y el número de referencia del estudiante. 
Es interesante como algo tan común y útil en nuestro día a día, como es un teléfono móvil, puede aportarnos conocimientos académicos a través de aplicaciones como esta. Por otro lado, también me parece importante el hecho de la autoevaluación, para que así el estudiante pueda conocer otros métodos de aprendizaje, además de ser un camino más fácil y dinámico para llegar al conocimiento. Por último, reiterando un poco las respuestas de mis compañeros, la comodidad a la hora de utilización es absoluta, pues no dependes de horarios ni de asistencias escolares. (GExp_32)

Más allá de los múltiples comentarios que se podrían haber incluido, y como cierre del análisis de la metodología m-learning y del uso de la aplicación móvil, se realizó una ingeniería de datos mediante conglomerados con el software NVivo 11 - Figura 5 -, en forma de nube de palabras, de los aspectos positivos y mejorables que se indicaron en los foros virtuales desarrollados a lo largo del experimento:



Figura 5: Conglomerados de palabras.

Ambas imágenes muestran la gran diferencia existente entre la concepción positiva y la negativa. Vistos los aspectos positivos que subyacen en los testimonios anteriormente indicados, los términos que hacían referencia a mejoras de la aplicación se dividen en dos direcciones: la primera, donde se aprecia el término iphone, es una queja referida al sistema operativo de la aplicación ya que no estaba disponible para IOS; y, la segunda, con términos como dificultad, ejercicios, niveles, básicas, hacen alusión a una demanda de mayor número de ejercicios y que hubiese niveles de dificultad en la aplicación: "destacaría la inclusión de un mayor número de ejercicios o de otro tipo de ejercicios de una mayor dificultad o precisión, algo que creo que sería fácil de llevar a cabo" (GExp_31).

\subsection{El postest: análisis de programa educativo implementado}

La segunda prueba de diagnóstico - postest - se aplicó a los dos grupos de 
estudio. El modelo de cuestionario fue equivalente al inicial - Anexo 1. La media obtenida evidenció una mejoría del grupo experimental (valor 1,5373) frente a la del grupo control (valor 1,4482), que, incluso, decreció respecto al pretest. Respecto a la actuación metalingüística del grupo experimental - Figura 6 -, tanto en morfología $(1,5117)$ como en sintaxis $(1,5629)$, la media es superior que la del grupo control. Este hecho evidencia un mayor avance en la competencia gramatical tras el experimento.

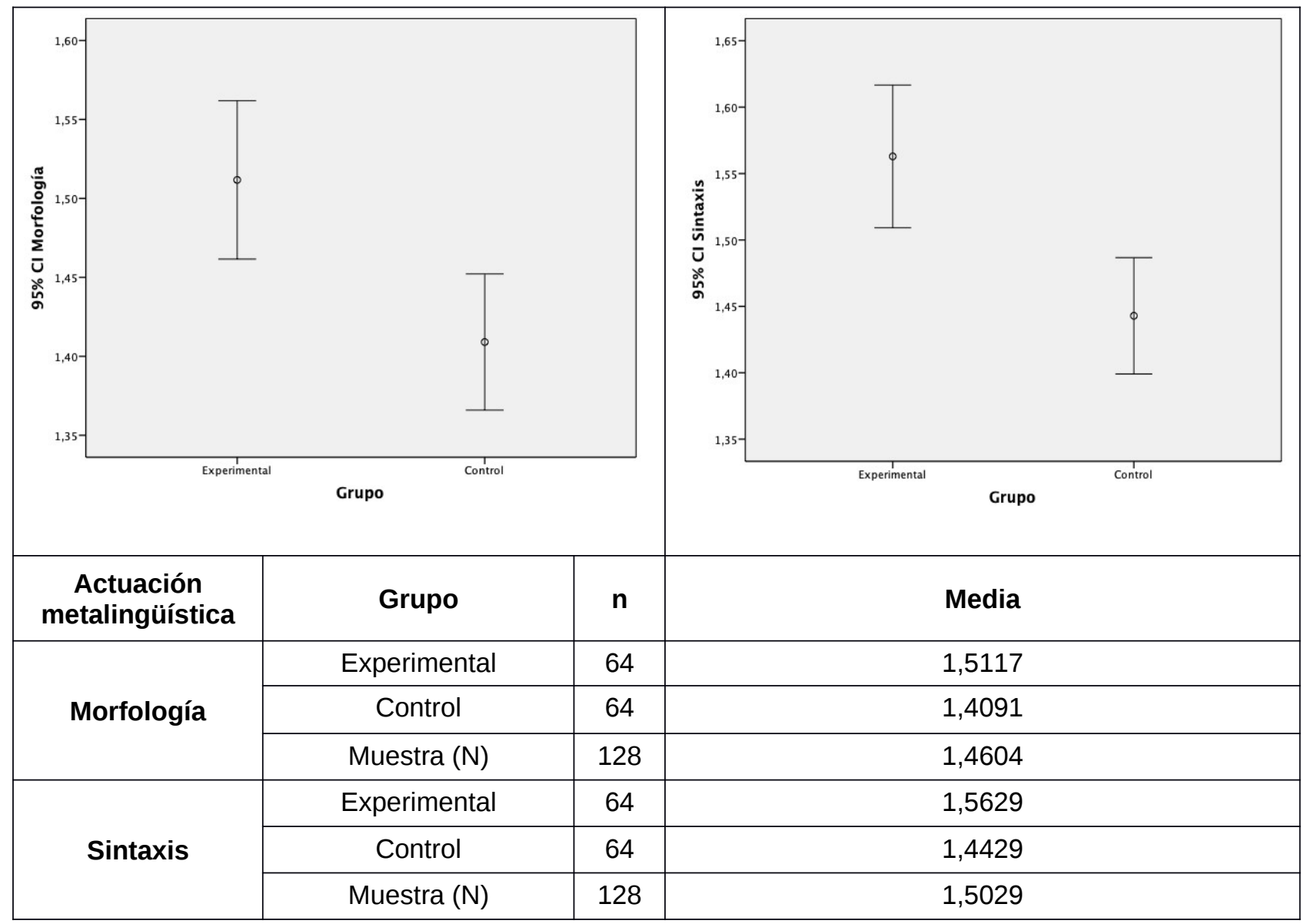

Figura 6: Postest. Descriptivos según variable actuación metalingüística.

La evolución de las respuestas en el gráfico radial - Figura 7 - ofrece una evidente mejoría del grupo experimental respecto al grupo control en los 20 ítems del cuestionario del postest, lo que nos hace confirmar inicialmente la hipótesis válida en la que el uso de la aplicación móvil, centrada en una metodología e-learning, ejerció como variable independiente en la mejora de la competencia gramatical. 




Figura 7: Postest. Tasas de éxito porcentual del grupo control y del grupo experimental.

Además, el tercer aspecto que fue objeto de estudio fue la evolución del dominio según los estudios de procedencia. La tasa de éxito de las tres categorías de análisis obtuvo una progresión significativa en el grupo experimental - Tabla 11: bachillerato (mostró una mejora de 12,9\%, alcanzando el 53,9\%), siendo los otros grados universitarios (de $35 \%$ al $67,5 \%$ en el postest) y los estudios procedentes de ciclo superior (de 29,2\% al 55\%). Esta evolución es aún más relevante si se compara con la producida en el grupo control, donde no hubo una intervención del uso de la aplicación móvil (elearning). Podemos observar cómo existe una gran diferencia en las tasas de éxito entre el grupo control -con resultados que no llegan a superar un incremento pretest-postest del $10 \%$, llegando incluso a decrecer en el grupo de bachillerato-.

Tabla 11: Postest. Tasas de éxitos porcentuales de dominio gramatical por estudio de procedencia.

\begin{tabular}{|l|c|c|c|c|c|c|}
\hline \multirow{2}{*}{$\begin{array}{c}\text { Ámbito } \\
\text { lingüístico }\end{array}$} & \multirow{2}{*}{ Ítem } & \multicolumn{2}{|c|}{ Bachillerato } & \multicolumn{2}{c|}{ Ciclo superior } & Universidad \\
\cline { 3 - 7 } & & \multicolumn{2}{|c|}{ Tasas de éxito (\%) } & \multicolumn{2}{c|}{ Tasas de éxito (\%) } & $\begin{array}{c}\text { Tasas de } \\
\text { éxito (\%) }\end{array}$ \\
\cline { 3 - 7 } & & Control & Experim. & Control & Experim. & Control \\
\hline \multirow{2}{*}{ Morfología } & 1 & 57,8 & 67,8 & 50,0 & 50,0 & 80,0 \\
\cline { 2 - 7 } & 2 & 70,2 & 86,4 & 50,0 & 100 & 100 \\
\cline { 2 - 7 } & 3 & 57,4 & 66,7 & 75,0 & 50,0 & 40,0 \\
\hline
\end{tabular}




\begin{tabular}{|c|c|c|c|c|c|c|}
\hline \multirow{5}{*}{} & 4 & 36,2 & 49,2 & 50,0 & 0,0 & 20,0 \\
\cline { 2 - 7 } & 5 & 23,4 & 33,3 & 36,4 & 50,0 & 40,0 \\
\cline { 2 - 7 } & 6 & 23,9 & 25,9 & 18,2 & 100 & 25,0 \\
\cline { 2 - 7 } & 7 & 2,2 & 30,5 & 58,3 & 50,0 & 20,0 \\
\cline { 2 - 7 } & 8 & 6,4 & 25,4 & 16,7 & 0,0 & 20,0 \\
\hline \multirow{6}{*}{ Sintaxis } & 9 & 76,6 & 73,3 & 41,7 & 100 & 80,0 \\
\cline { 2 - 7 } & 10 & 70,2 & 90,0 & 41,7 & 100 & 100 \\
\cline { 2 - 7 } & 11 & 74,5 & 91,5 & 54,5 & 100 & 60,0 \\
\cline { 2 - 7 } & 12 & 6,5 & 11,7 & 9,1 & 0,0 & 40,0 \\
\cline { 2 - 7 } & 13 & 70,2 & 71,7 & 41,7 & 100 & 100 \\
\cline { 2 - 7 } & 14 & 46,8 & 51,7 & 50,0 & 50,0 & 80,0 \\
\cline { 2 - 7 } & 16 & 38,3 & 41,4 & 58,3 & 50,0 & 40,0 \\
\cline { 2 - 7 } & 17 & 53,3 & 84,2 & 50,0 & 50,0 & 40,0 \\
\cline { 2 - 7 } & 18 & 12,8 & 38,3 & 16,7 & 0,0 & 80,0 \\
\cline { 2 - 7 } & 19 & 46,8 & 45,8 & 58,3 & 50,0 & 40,0 \\
\cline { 2 - 7 } & 20 & 25,5 & 33,9 & 16,7 & 50,0 & 0,0 \\
\hline
\end{tabular}

Finalmente, el análisis de la evolución pretest-postest en el grupo experimental presentó una tendencia de mejora significativa - Tabla 11: los resultados revelaron un incremento de la tasa de éxito en 18 de los 20 ítems de los cuestionarios que se emplearon para el diagnóstico de la competencia gramatical - solo los ítems 15 y 19 , correspondientes a la sintaxis, tuvieron peor resultado en el postest. la progresión en las tasas de éxito se hizo evidente en el resto de ítems, mejorando la media porcentual tanto en el ámbito de la morfología (

Sin embargo, no podemos obviar que existen ítems con resultados inferiores al 50\% - tanto en morfología (ítems 5, 6, 7 y 8) como en sintaxis (ítems 12, 15, 18 y 19). Este dato justifica la idea de que, a pesar de la evolución observada en el grupo experimental, es preciso seguir avanzando en el dominio competencial de la gramática en los estudiantes.

\section{Conclusiones}

Esta investigación cuasi experimental ha pretendido arbitrar una estrategia basada en la metodología e-learning en donde el uso de una aplicación móvil ha sido la referencia para la autonivelación de los estudiantes de nuevo ingreso del Grado en Educación Primaria. Los resultados han demostrado la validez del experimento al obtenerse una diferencia en la tasa de dominio desde una doble concepción: una primera diferencia con respecto al grupo control puesto que, siendo similares la medias de tasas de éxito en el pretest (39,6\%, en grupo control y 42,9\%, en grupo experimental), la progresión mostrada por el grupo experimental en el postest $(54,1 \%)$ fue superior a la del grupo control $(42,7 \%) ; y$, una segunda diferencia en la progresión intragrupal en el proceso pretest- 
postest del experimento (42,9\%- 54,2\%).

El análisis de la variable de los estudios de procedencia sirvió para afrontar otro de los retos que nos encontramos en las aulas universitarias: la diversidad de niveles conceptuales en el dominio gramatical de los estudiantes que han realizado los estudios de bachillerato, donde se incluyen contenidos de reflexión metalingüística, y los de ciclo superior, que no se abordan en ellos. Los resultados de los estudiantes, que partían con un porcentaje en el pretest de $29,2 \%$, alcanzaron un $55 \%$ en el postest (mientras que este grupo de estudiantes tuvo una evolución del 30\% al 39,2\% en las pruebas realizadas). De esta forma, se evidencia que la metodología empleada sirvió también para la autonivelación y autogestión del aprendizaje de un grupo desde la diversidad del aula.

Entre las aportaciones más destacables de esta investigación señalamos la verificación de la adecuación de la tecnología a través de un cuestionario TAM. Este ofreció unos índices muy elevados (79,6\% de aceptación) respecto a las tres dimensiones analizadas sobre el uso de la aplicación: facilidad, motivación y utilidad. Esta idea fue completada por la propia voz de los estudiantes que durante todo el experimento tuvieron activo un foro virtual donde iban compartiendo su experiencia. Ambas estrategias sirvieron para cerrar la investigación y realizar una matriz DAFO en la que confluyen todas las perspectivas de la investigación: los resultados del experimento pretest-postest, la voz de los estudiantes (TAM y foro educativo), y, por último, la observación y análisis de resultados de los investigadores:

Tabla 12: Matriz DAFO.

\begin{tabular}{|c|c|}
\hline Análisis de las causas internas & Análisis de las causas externas \\
\hline Debilidades & Amenazas \\
\hline $\begin{array}{l}\text { - Los niveles de la competencia gramatical de los } \\
\text { estudiantes de nuevo ingreso son bajos en relación con el } \\
\text { conocimiento de la propia lengua -morfología y sintaxis. } \\
\text { Esta situación exige una nivelación competencial que } \\
\text { no se contemplan en los programas de las } \\
\text { asignaturas. Además, existe una gran diversidad de } \\
\text { niveles en el aula, vinculada a la procedencia de los } \\
\text { estudiantes (Bachillerato, Ciclos Superiores y } \\
\text { Universidad). } \\
\text { La motivación por el estudio de la lengua es baja, a } \\
\text { pesar de convertirse en objeto de enseñanza en su } \\
\text { futura profesión docente. } \\
\text { Aspectos técnicos y de acceso a las tecnologías } \\
\text { (Android, IOS, wifi...). }\end{array}$ & $\begin{array}{l}\text { - La cultura de enseñanza en los estudios } \\
\text { superiores debe adaptarse a las necesidades } \\
\text { de los estudiantes y crear espacios y } \\
\text { estrategias formativas para la nivelación de } \\
\text { sus estudiantes. } \\
\text { El sistema de competencias prescritas en los } \\
\text { diseños de los grados universitarios ofreció } \\
\text { una rigidez al relatar. } \\
\text { La competencia digital para el desarrollo } \\
\text { académico no está interiorizado en los } \\
\text { estudiantes, más cercana a los aspectos } \\
\text { sociales. }\end{array}$ \\
\hline Fortalezas & Oportunidades \\
\hline $\begin{array}{l}\text { - Los proyectos de innovación docentes que ofrecen las } \\
\text { universidades posibilitan una reflexión para afrontar los } \\
\text { problemas detectados de cara al desarrollo de las asignaturas. } \\
\text { La alfabetización en medios por parte de los } \\
\text { estudiantes es una alternativa de actuación hacia } \\
\text { metodologías activas, como m-learning. } \\
\text { - La mediación docente a través de las plataformas } \\
\text { virtuales de asignaturas facilitan el asesoramiento y } \\
\text { orientación en la autonivelación de los estudiantes. }\end{array}$ & $\begin{array}{l}\text { - La existencia de aplicaciones móviles (app) y } \\
\text { de plataformas virtuales con materiales para } \\
\text { la nivelación gramatical ofrece un nuevo } \\
\text { modelo de aprendizaje autónomo y } \\
\text { autorregulado (m-learning, b- learning...) en } \\
\text { torno al estudiante. }\end{array}$ \\
\hline
\end{tabular}

Así, aunque los resultados de esta investigación no pretenden ser generalizados al 
tratarse de un estudio cuasi experimental realizado en la Universidad de Cádiz, consideramos que se ha contribuido a afrontar un reto en los estudios de grado de magisterio: la nivelación epistemológica de diversas disciplinas. Abogamos y apostamos por las posibilidades de las metodologías activas que tienen cabida en escuela actual, en nuestro caso, mobile learning, en donde confluyen la autogestión del aprendizaje y las aplicaciones móviles.

\section{Referencias}

AGUADED, J. I.; PÉREZ RODRÍGUEZ, M. A. La educación en medios de comunicación como contexto educativo en un mundo globalizado. En: CABERO, J. (coord.). Nuevas Tecnologías Aplicadas a la Educación. Madrid: McGraw-Hill, 2006. p. 63-76.

AJZEN, I.; FISHBEIN, M. Understanding attitudes and predicting social behaviour. Englewood Cliffs, NJ: Prentice-Hall, 1980.

BRAZUELO GRUND, F.; CACHEIRO GONZÁLEZ, M. L. Diseño de páginas web educativas para teléfonos móviles. Edutec: Revista electrónica de tecnología educativa, v.32, n. 2. p. 1-14, 2010. Disponible en: https://bit.ly/2lodMKP. Acceso en: 3 ene. 2019.

BRAZUELO, F. ; GALLEGO, D. J. Estado del Mobile Learning en España. En: Educar em Revista, Curitiba, Brasil, Edição Especial, n. 4, p. 99-128, 2014. Disponible en: https://bit.ly/2kaAclq. Acceso en: 4 ene. 2019

CABERO, J. Bases pedagógicas del e-learning. Revista de Universidad y Sociedad del Conocimiento, v.3 n.1, 2006. Disponible en: https://bit.ly/1cdgXtd . Acceso en: 4 ene. 2019.

CAMPBELL, D. y STANLEY, J. Diseños experimentales y cuasi experimentales en la investigación social. Buenos Aires: Amorrortu, 1966.

CARRIÓ PASTOR, M. L. Technology implementation in second language teaching and translation studies. Singapore: Springer, 2016.

COLÁS BRAVO, P. La investigación-acción. En: COLÁS, P. y BUENDÍA, L. (Coords) Investigación educativa. Sevilla: Ediciones Alfar, 1998, p .250-260.

COLL, C. Psicología de la educación y prácticas educativas mediadas por las tecnologías de la información y la comunicación. Una mirada constructivista. Revista Electrónica Sinéctica, n. 25, p. 1-24, 2004. Disponible en: https://bit.ly/2KIrgQI. Acceso en: 4 ene. 2019.

COMISIÓN EUROPEA. Competencias clave para el aprendizaje permanente. Un marco de referencia europeo. Luxemburgo: Oficina de Publicaciones Oficiales de las Comunidades Europeas, 2007. Disponible en: https://bit.ly/2WX5Wvu. Acceso en: 3 ene. 2019. 
CONSEJO DE EUROPA. Marco común europeo de referencia para las lenguas: aprendizaje, enseñanza, evaluación. Madrid: Secretaría General Técnica del MEC, Anaya e Instituto Cervantes, 2002.

CONTRERAS, J. Ser y saber en la formación didáctica del profesorado: una visión personal. Revista Interuniversitaria de Formación del Profesorado, v. 68, n. 24,2, p. 61-81, 2010.

CUADROS R.; VILLATORO, J. Twitter en la enseñanza y aprendizaje del español. Málaga: Digitalingua, Editorial Ediele, 2014.

CUESTA, I. I., ABELLA, V. y ALEGRE, J.M. Evaluación del módulo de cuestionarios del entorno de trabajo UBUVirtual mediante el modelo de Aceptación Tecnológica. Profesorado. Revista de currículum y formación del profesorado, v. 19, n. 1, p. 431-445, 2014.

DAVIS, F. D. Perceived usefulness, perceived ease of use, and user acceptance of information technology. MIS Quarterly, v. 13, n. 3, p. 319-340, 1989.

ERDOCIA ÍÑIGUEZ, I. El aprendizaje autónomo a través de las redes sociales. RedELE, Biblioteca Virtual 2012, 2012.

FERNÁNDEZ ULLOA, T. Facebook y Twitter en la enseñanza del español como lengua extranjera. En: XVII Congreso Internacional de Tecnologías para la Educación y el Conocimiento, 2012, Madrid, UNED.

GARGIULO, H.; GARGIULO, E.; FERNÁNDEZ, C. Tecnología y metodología en la clase de ELE. Buenos Aires: Tinta Fresca, 2015.

GIKAS, J.; GRANT, M.M. Mobile computing devices in higher education: Student perspectives on learning with cellphones, smartphones \& social media. Internet and Higher Education, n. 19, p. 18-26, 2013.

GROS, B.; CONTRERAS, D. La alfabetización digital y el desarrollo de competencias ciudadanas. Revista Iberoamericana de educación, 42, p. 103-125, 2006. Disponible en: https://bit.ly/2UsXTK8. Acceso en: 3 ene. 2019.

GUERRA, S.; GONZÁLEZ, N.; GARCÍA, R. Utilización de las TIC por el profesorado universitario como recurso didáctico. Comunicar, v. 18 n. 35, p. 141-148, 2010.

GUTIÉRREZ MARTíN, A. Alfabetización digital. Algo más que ratones: teclas. Barcelona: Editorial Gedisa, 2003.

HERRERA, S. I.; FÉNNEMA, M. C. Tecnologías móviles aplicadas a la educación superior. En: Congreso Argentino de Ciencias de la Computación, XVII, 2011, Argentina, Actas, p. 620-630. Disponible en: https://bit.ly/2VuSkre. Acceso en: 3 ene. 2019. 
HINOJO, F. J; AZNAR, I.; ROMERO, J. Ma . Dispositivos móviles para el aprendizaje: análisis de la investigación doctoral sobre mobile learning en España. Texto Livre: Linguagem e Tecnologia, v. 11, n. 3, p. 154-175, 2018. Disponible en: https://bit.ly/2GcwqUp. Acceso en: 29 ene. 2019.

IMBERNÓN, F. Actualidad y nuevos retos de la formación permanente. Revista Electrónica de Investigación Educativa, v. 8 n. 2, 2006. Disponible en: https://bit.ly/2Ge2Ca1. Acceso en: 29 dic. 2018.

INSTITUTO CERVANTES. Las competencias clave del profesorado de lenguas segundas y extranjeras. Madrid: Instituto Cervantes, 2012.

JIMENEZ, F.; ROMERO, M. Fco; HEREDIA, H. Formación inicial del maestro y competencia gramatical para su práctica docente. Revista Humanidades UNED, n. 37, 2019 (en prensa).

LATORRE, A.; DEL RINCÓN, D.; ARNAL, J. Bases metodológicas de la investigación educativa. Barcelona: Ediciones Experiencias, 2005.

MARTÍNEZ SÁNCHEZ, F. La integración escolar de las nuevas tecnologías. En: CABERO J. (coord.), Nuevas Tecnologías Aplicadas a la Educación. Madrid: McGraw-Hill, 2006. p. 21-40.

MCMILLAN, J. H.; SCHUMACHER, S. Investigación educativa. Una introducción conceptual. Madrid: Pearson Educación, 2005.

MOLINA, M.; CASTRO, E.; MOLINA, J.; CASTRO, E. Un acercamiento a la investigación de diseño a través de los experimentos de enseñanza. Enseñanza de las ciencias, vol. 1, n. 29, p. 75-88, 2011.

PISANT, A.; ENRÍQUEZ, L.; CHAOS-CADOR, L.; GARCÍA BURGOS, M. M-learning en ciencia. Introducción de aprendizaje móvil en Física. Revista Iberoamericana de Educación a Distancia, v. 13 n. 1, p. 129-155, 2010. Disponible en: https://bit.ly/2InVM30. Acceso en 3 ene. 2019.

PRENSKY, M. Enseñar a nativos digitales. Una propuesta pedagógica para la sociedad del conocimiento. Madrid: Ediciones SM, 2010/2011.

RODRÍGUEZ ILLERA, J. L. Las alfabetizaciones digitales. Bordón. Revista de Pedagogía, v. 56, n. 3-4, p. 431-441, 2004. Disponible en: https://bit.ly/2IfiN9l. Acceso en: 3 ene. 2019.

SANDÍN ESTEBAN, M. P. Investigación cualitativa en educación: fundamentos y tradiciones. Madrid: McGraw-Hill España, 2003.

SIERRA, J. E.; CAPARRÓS, E.; MOLINA, D.; BLANCO, N. Aprender a través de la escritura. Los diarios de prácticas y el desarrollo de saberes experienciales. Revista Complutense de Educación, v. 28, n. 3, p. 673-688, 2017. 
VARO DOMÍNGUEZ, D.; CUADROS MUÑOZ, R. Twitter y la enseñanza del español como segunda lengua, RedELE: Revista Electrónica de Didáctica. Español como lengua española, n. 25, 2013. Disponible en: https://bit.ly/2G5zyQN. Acceso en: 3 ene. 2019.

VÁZQUEZ-CANO, E.; SEVILLANO, M. L. Dispositivos digitales móviles en educación. Madrid: Narcea, 2015.

WINER, L.; VÁZQUEZ, J. Seminario sobre la integración de las TIC en la enseñanza. Costa Rica: Universidad Nacional, 2002.

WOODILL, G. The mobile learning edge. Nueva York: McGraw-Hill, 2011.

Recebido em dia 10 de abril de 2019. Aprovado em dia 29 de abril de 2019. 


\section{ANEXOS \\ Prueba De Nivelación En Competencia Gramatical (Morfosintaxis)}

\begin{tabular}{|c|c|}
\hline \multicolumn{2}{|c|}{ Nombre y apellidos: } \\
\hline Procedencia: & Otro (Indíquelo): \\
\hline Ítem 1 & $\begin{array}{l}\text { Identifique los adjetivos (calificativos o relacionales) que aparecen en la siguiente } \\
\text { oración: }\end{array}$ \\
\hline Pretest & El escritor mexicano cultura una prosa clásica y exquisita \\
\hline Postest & $\begin{array}{l}\text { Rumanía es un destino poco turístico, sin embargo, cuenta con paisajes } \\
\text { espectaculares. }\end{array}$ \\
\hline Ítem 2 & Identifique los sustantivos que aparecen en la siguiente oración: \\
\hline Pretest & El ayuntamiento de Málaga prohíbe fumar en las plazas de toros. \\
\hline Postest & Los investigadores piden a la ciudadanía que aporten pruebas \\
\hline Ítem 3 & $\begin{array}{l}\text { Escoja el tiempo verbal que se corresponda con el verbo en negrita del siguiente } \\
\text { ejemplo en modo indicativo que se muestra a continuación: }\end{array}$ \\
\hline Pretest & $\begin{array}{l}\text { Acomodaste perfectamente la mercancía } \\
\text { a. Futuro simple } \\
\text { b. Pretérito perfecto simple } \\
\text { c. Pretérito imperfecto }\end{array}$ \\
\hline Postest & $\begin{array}{l}\text { Si pulsas el botón, se activa la señal de alarma } \\
\text { a. Pretérito imperfecto } \\
\text { b. Presente simple } \\
\text { c. Condicional simple }\end{array}$ \\
\hline Ítem 4 & $\begin{array}{l}\text { Escoja la forma verbal que se corresponda con el verbo del siguiente ejemplo en } \\
\text { modo imperativo que se muestra a continuación }\end{array}$ \\
\hline Pretest & $\begin{array}{l}\text { Os he dicho ya muchas veces que estoy cansada: no } \\
\text { mientras estoy durmiendo (segunda persona del plural del imperativo del verbo } \\
\text { "mover" } \\
\text { a. Moved } \\
\text { b. Mováis } \\
\text { c. Mover }\end{array}$ \\
\hline Postest & $\begin{array}{l}\text { Tras la discusión que protagonizaron en la oficina, el jefe les dijo muy enfadado: } \\
\text { "no hasta que solucionéis todos los problemas que tenéis entre } \\
\text { vosotros" (segunda persona del plural de imperativo del verbo "venir" } \\
\text { a. Venir } \\
\text { b. Venid } \\
\text { c. Vengáis }\end{array}$ \\
\hline Ítem 5 & Identifique los adjetivos determinativos y artículos de la siguiente oración: \\
\hline Pretest & $\begin{array}{l}\text { El agua es un buen componente para nuestro cuerpo y más cuando hacemos } \\
\text { bastante deporte. }\end{array}$ \\
\hline Postest & $\begin{array}{l}\text { Sería interesante que tú resolvieses aquellos problemas que has ocasionado en } \\
\text { muchas situaciones. }\end{array}$ \\
\hline Ítem 6 & Identifique las conjunciones coordinadas de la siguiente oración: \\
\hline Pretest & Me dijo que no tenía ni para comer pan \\
\hline
\end{tabular}




\begin{tabular}{|c|c|}
\hline Postest & Mas sabemos que quienes nos comprenden, nos esclavizan \\
\hline Ítem 7 & Identifique los pronombres de la siguiente oración \\
\hline Pretest & Aquella, que estás viendo, ha sido la causante de nuestra separación. \\
\hline Postest & ¿Quién quemó las actas que le había dado al secretario? \\
\hline Ítem 8 & Identifique los adverbios de la siguiente oración: \\
\hline Pretest & $\begin{array}{l}\text { Probablemente, después de los enfrentamientos producidos en Turquía, no irán } \\
\text { muchas personas a visitar ese país }\end{array}$ \\
\hline Postest & Anoche cuatro personas se encadenaron aquí para protestar por la tala de árboles \\
\hline Ítem 9 & Identifique las preposiciones de la siguiente oración: \\
\hline Pretest & Nuevas pistas sobre el paradero del alpinista desaparecido \\
\hline Postes & En la zapatería de la esquina tienen las sandalias que estás buscando \\
\hline Ítem 10 & Señale el sujeto de la siguiente oración \\
\hline Pretest & A Carlos siempre le ilusionan los cambios \\
\hline Postest & La subida de intereses siempre sorprendía a las ciudadanía \\
\hline Ítem 11 & Identifique el complemento de régimen preposicional en la siguiente oración: \\
\hline Pretest & En las elecciones la participación dependerá de la campaña política \\
\hline Postest & Al fin mi amor disfruta de la vida \\
\hline Ítem 12 & Identifique el complemento predicativo en la siguiente oración: \\
\hline Pretest & Marta llegó radiante anoche \\
\hline Postest & Felipe salió elegido alcalde hace tres años \\
\hline Ítem 13 & Identifique el complemento indirecto en la siguiente oración \\
\hline Pretest & Almudena pidió a Claudio las llaves \\
\hline Postest & Me lo contaron con detalle \\
\hline Ítem 14 & Señale el complemento directo en la siguiente oración \\
\hline Pretest & Algo así necesitaría yo para el camping \\
\hline Postest & Aquello sembró la duda en su matrimonio \\
\hline Ítem 15 & Señale: \\
\hline Pretest & $\begin{array}{l}\text { El tipo de complemento circunstancial "así" en la siguiente oración: Bernarda hizo } \\
\text { así sus tareas }\end{array}$ \\
\hline Postest & $\begin{array}{l}\text { El tipo de complemento circunstancial "sin parar" en la siguiente oración: Desde } \\
\text { ayer está nevando sin parar en Polonia }\end{array}$ \\
\hline Ítem 16 & $\begin{array}{l}\text { Señale, en la siguiente oración, el sintagma que desempeña la función de } \\
\text { complemento agente: }\end{array}$ \\
\hline Pretest & $\begin{array}{l}\text { El barrio alto de la ciudad ha sido declarado recientemente, por sorpresa, } \\
\text { patrimonio nacional por la UNESCO }\end{array}$ \\
\hline Postest & $\begin{array}{l}\text { Por fortuna, aquel polizón de a bordo fue descubierto rápidamente por el agente } \\
\text { secreto }\end{array}$ \\
\hline Ítem 17 & Identifique el tipo de coordinada: \\
\hline
\end{tabular}




\begin{tabular}{|c|c|}
\hline Postest & $\begin{array}{l}\text { María es muy inteligente en los estudios, pero estudia poco } \\
\text { a. Copulativa } \\
\text { b. Disyuntiva } \\
\text { c. Adversativa }\end{array}$ \\
\hline Pretest & $\begin{array}{l}\text { La cena está ya preparada, así que recibamos a los invitados } \\
\text { a. Copulativa } \\
\text { b. Explicativa } \\
\text { c. Consecutiva }\end{array}$ \\
\hline Ítem 18 & Identifique la función que desempeña la subordinada sustantiva \\
\hline Pretest & $\begin{array}{l}\text { Me gusta que me acompañes a la fiesta del colegio } \\
\text { a. Sujeto } \\
\text { b. } C D \\
\text { c. Atributo }\end{array}$ \\
\hline Postest & $\begin{array}{l}\text { Mis amigos y yo aspiramos a ganar el premio de pintura } \\
\text { a. Cl } \\
\text { b. CP } \\
\text { c. CD }\end{array}$ \\
\hline Ítem 19 & Identifique la clase de oración subordinada \\
\hline Pretest & $\begin{array}{l}\text { He guardado las llaves de la casa donde te explicó tu hermana } \\
\text { a. Lugar } \\
\text { b. Concesiva } \\
\text { c. Final }\end{array}$ \\
\hline Postest & $\begin{array}{l}\text { Me lo corregirá el maestro para que observe los errores } \\
\text { a. Final } \\
\text { b. Causal } \\
\text { c. concesiva }\end{array}$ \\
\hline Ítem 20 & Identifique la función sintáctica que desempeña el nexo subordinante \\
\hline Pretest & $\begin{array}{l}\text { La casa que está junto al pantano pertenece a mis tíos } \\
\text { a. } S \text { ujeto } \\
\text { b. } C D \\
\text { c. Atributo }\end{array}$ \\
\hline Postest & $\begin{array}{l}\text { Ayer vimos la película que nos recomendaste } \\
\text { a. Sujeto } \\
\text { b. } C D \\
\text { c. Cl }\end{array}$ \\
\hline
\end{tabular}

